\title{
Research Paper \\ The Effect of Phantom Compositions on Dose Calculations in Proton Therapy of Liver Cancer
}

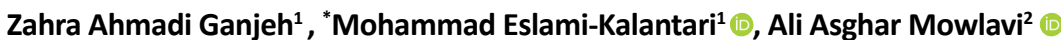

1. Department of Physics, School of Science, Yazd university, Yazd, Iran.

2. Department of Physics, Faculty of Basic Sciences, Campus of Basic Sciences, Hakim Sabzevari University, Sabzevar, Iran.

\begin{tabular}{|c|c|}
\hline $\begin{array}{l}\text { Use your device to scan } \\
\text { and read the article online }\end{array}$ & Clt tat on: Ahmadi Ganieh Z Eslami-Kalantari M MowlaviAA [The Effect of Phantom Comnositions on Dose Calculations \\
\hline 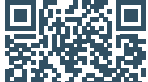 & $\begin{array}{l}\text { in Proton Therapy of Liver Cancer (Persian)]. Journal of Arak University of Medical Sciences (JAMS). 2020; 22(6):274-287. } \\
\text { https://doi.org/10.32598/JAMS.22.6.6019.1 }\end{array}$ \\
\hline 口ifesis & dol'https://doi.org/10.32598/JAMS.22.6.6019.1 \\
\hline
\end{tabular}

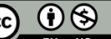

Article Info:

Received: 26 Oct 2019 Accepted: 24 Dec 2019 Available Online: 01 Feb 2020

Key words:

Proton therapy,

Simulation, Liver

cancer, Spread-out

Bragg Peaks, Dose

distribution

\section{ABSTRACT}

Background and Aim Sicne in many dosimetry calculations, the water and soft tissue phantoms are used, this study aimed to investigate the difference of these two phantoms with a phantom consisted of realistic liver materials in proton therapy for liver cancer.

Methods \& Materials Three phantoms with different materials of water, soft tissue and realistic liver materials were used for the study. A spherical tumor with $2 \mathrm{~cm}$ radius was considered in the liver. The Spreadout Bragg Peaks (SOBPs) were measured to cover the complete tumor for the three phantoms. Dose distribution and deposited dose ratio in tumor and surrounding organs were calculated using Monte Carlo N-Particle Extended (MCNPX) code.

Ethical Considerations The best proton energy interval to complete the coverage of tumor in the liver for phantoms with realistic and soft tissue materials was 90-120 MeV and for water phantom, it was 88-116 MeV. The shift of the Bragg peaks depth per energy in the water phantom mm relative to two other phantoms was about 4.5. The dose parameters were evaluated according to the International Commission on Radiation Units and Measurements (ICRU), and the results showed no any significant difference between them. The dose distribution in the tumor and surrounding organs showed that for all three phantoms, the dose distribution around the tumor was negligible.

Results The use of soft tissue phantom has more acceptable results than water phantom in simulating treatment and can be replaced with realistic liver tissue. More realistic phantoms should be used in treatment plan.

Conclusion The use of soft tissue phantom has more acceptable results than water phantom in simulating treatment and can be replaced with realistic liver tissue. More realistic phantoms should be used in treatment plan.

\section{Extended Abstract}

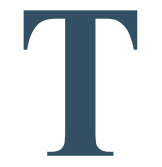

\section{Introduction}

he main goal to choose the most appropriate method for cancer treatment is the achievement of high dose deposition in the tumor while preserving the surrounding healthy tissue as much as possible. Protons have different dosimetric characteristics than photons used in conventional radiation therapy. After a short build-up region, conventional radiation shows an exponentially decreasing energy deposition with increas-

\section{* Corresponding Author}

Mohammad Eslami-Kalantari, PhD.

Address: Department of Physics, School of Science, Yazd university, Yazd, Iran.

Tel: +98 (35) 31232782

E-mail: meslami@yazd.ac.ir 
ing depth in tissue. In contrast, protons show an increasing energy deposition with penetration distance leading to a maximum (the "Bragg peak") near the end of range of the proton beam [1-5]. In this study, it has been attempted to predict appropriate conditions for proton therapy of liver cancer. Although different studies use water or soft tissue phantoms to perform dosimetry, here three phantoms such as soft tissue, water phantom and, a phantom consists of liver realistic material were simulated to observe their dosimetric differences.

\section{Methods and Materials}

The target was simulated as a spherical tumor with a radius of $2 \mathrm{~cm}$ in the liver, which is located inside the complete phantom of the human body. At the first step to obtain Bragg peaks in the tumor region, the proton source was considered as a single energy perpendicular to the phantom and the energy was changed by $2 \mathrm{MeV}$ steps. Phantoms 1 to 3 are made of soft tissue, liver realistic elements, and water, respectively. By adding a set of beams with different weight factors, a Spread-Out Bragg Peak (SOBP) is generated, which delivers the desired dose to the whole of the treatment target $[10,11]$. The Bragg peaks to cover the tumor were calculated and then the SOBP designed by calculating the weighting factors. The dose distribution in the tumor and surrounding areas, as well as the dose of the protons, secondary neutrons, and photons absorbed in the tumor and healthy organs around the tumor, were calculated and the results are compared for three phantoms. All of the simulations were carried by MCNPX.

\section{Results}

The results of this study consist of Bragg peak dose distributions, Bragg peak positions, determination of weighting factors, creating SOBP, and evaluation of deposited dose in tumor and healthy tissues. The proper proton beam ener-

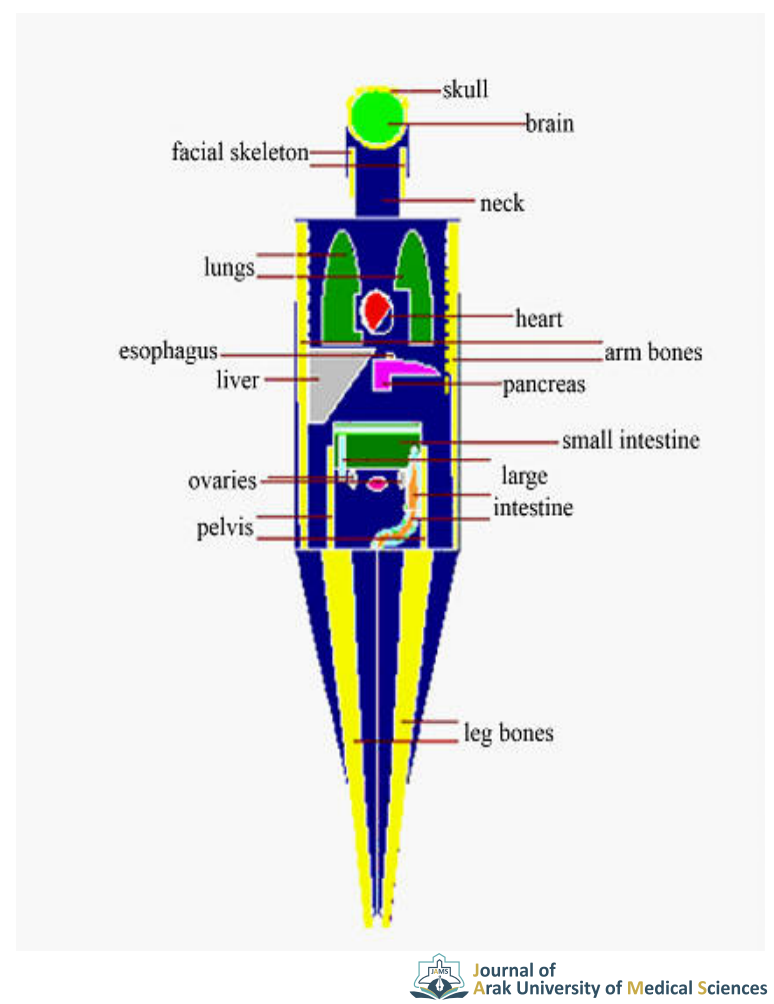

Figure 1. Bragg-peak positions within the liver tumor as a function of energy for three phantoms.

gies to cover tumor region and the Bragg peak positions for three phantoms are shown in Figure 1.

For phantoms 1 and 2, the coverage of tumor volume is done by using of Bragg peak energies about $90 \mathrm{MeV}-120$ $\mathrm{MeV}$. For phantom 3 the energy of first Bragg peak at the tumor surface is about $88 \mathrm{MeV}$ and the last one is about 116 $\mathrm{MeV}$. A uniform dose region is created by adding Bragg peaks for different proton energies by considering the appropriate weights to obtain a flat SOBP. The resultant SOBPs are presented in Figure 2.

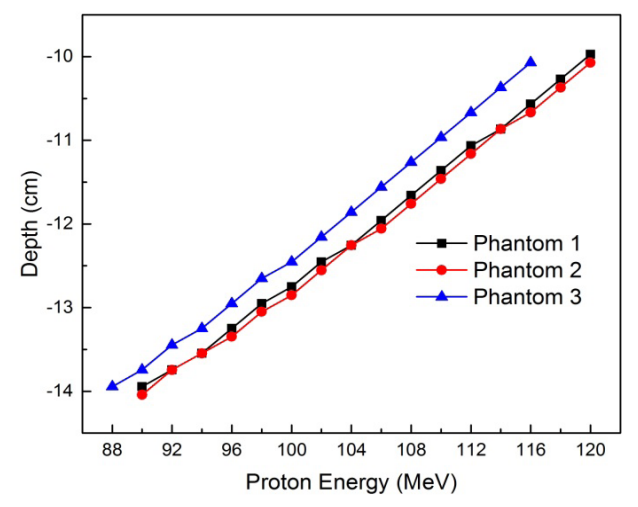

Figure 2. SOBPs for three phantoms 


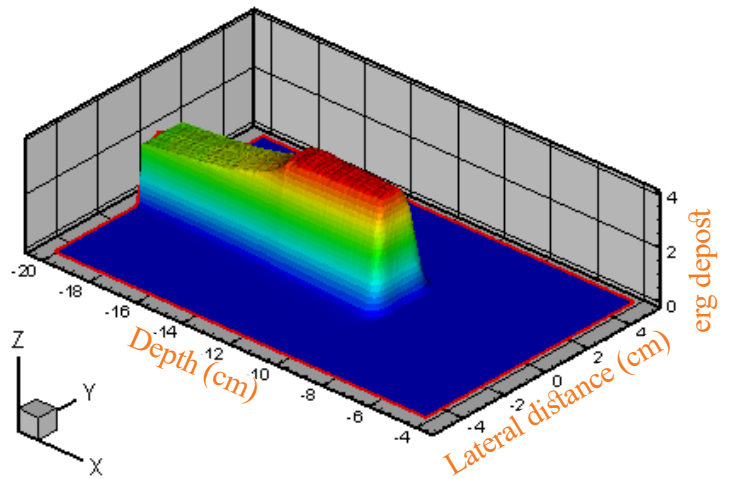

Figure 3. The ratio of the dose in the different organs based on the delivered dose to the tumor

The evaluated dose of protons, neutrons, and photons in the tumor and some organs around that for three phantoms were calculated. The ratio of deposited dose in noninvolved organs to the tumor was calculated and shown in Figure 3.

\section{Discussion}

In this study, the simulation of liver proton therapy for three phantoms consisting of soft tissue, realistic liver, and water was investigated to find the dosimetric differences. Suitable Bragg peaks were calculated to cover the tumor volume for the three phantoms. The results showed that for the soft tissue phantom and the phantom consisting of the realistic liver tissue, Bragg peaks to cover the tumor volume were in range of $90 \mathrm{MeV}-120 \mathrm{MeV}$ and for the water phantom it was about $88 \mathrm{MeV}-116 \mathrm{MeV}$. The dose deposited point for the water phantom at each energy was different from the other two phantoms and this difference was about $4.5 \mathrm{~mm}$ at each point. In order to cover the whole tumor volume, we have created SOBPs for three phantoms by using properly optimized weighting factors. It would be better to take in to account the realistic composition of different tissues of the phantom. Finally, the total dose of proton and secondary particles in the tumor and 22 non-involved organs were calculated. Dose calculations in different organs of the body showed that most parts of the body received dose and organs close to the liver such as the heart, stomach, pancreas, etc. received more doses than other organs. But this deposited dose is insignificant compared to the dose received by the tumor.

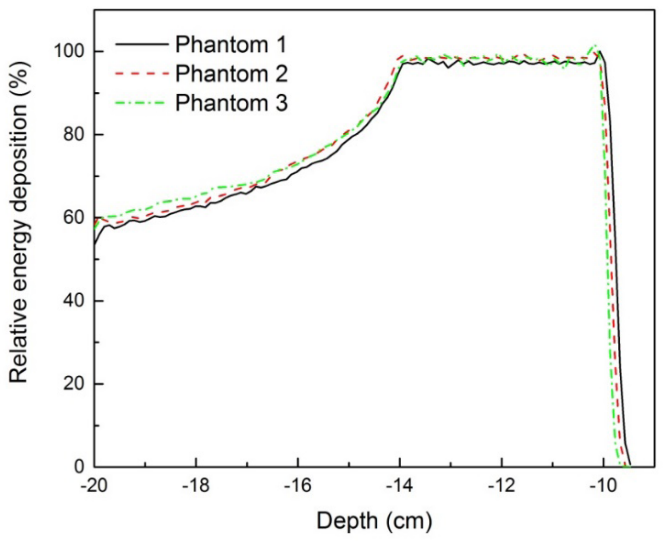
Journal of
Arak University of Medical Sciences J J rak University of Medical Sciences

\section{Ethical Considerations}

\section{Compliance with ethical guidelines}

Since there was no experiment on human or animal samples in this study, there was no need for ethical approval.

\section{Funding}

The present paper was extracted from a $\mathrm{PhD}$. thesis of the first author, Zahra Ahmadi ganjeh, approved by the Department of Physics, School of Science, Yazd University, Yazd, Iran.

\section{Authors' contributions}

All authors contributed equally in preparing all parts of the research.

\section{Conflicts of interest}

The authors declared no conflict of interest. 


\title{
تأثير عناصر تشكيلدهنده فانتوم بر محاسبات دز در يروتونترايى سرطان كبد
}

\author{
زهرا احمدى كنجه'، "محمد اسلامى كلانترى ๑'، على اصغر مولوى' \\ ا. ا.كروه هسته اي، دانشكده فيزيك، يرديس علوم هايه، دانشُكاه يزد، يزده، ايران.

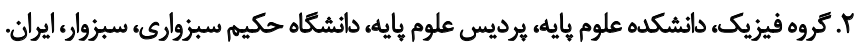

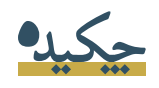

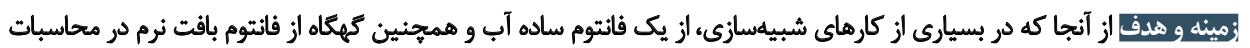

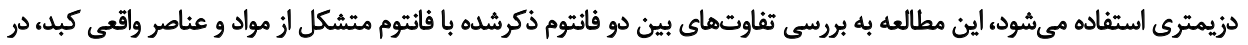

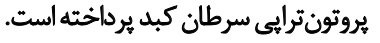

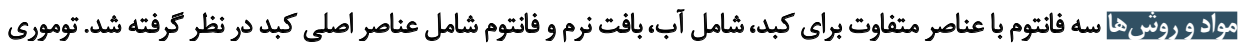

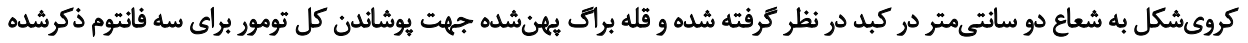

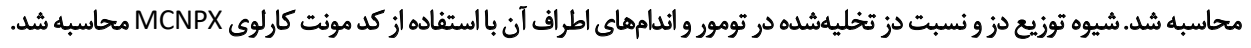

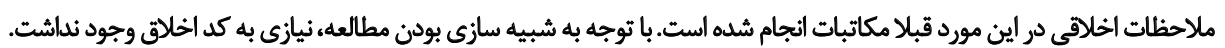

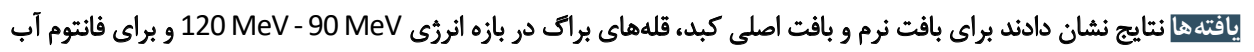

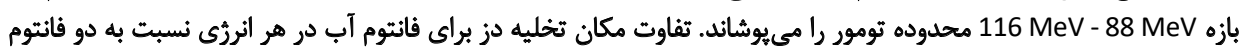

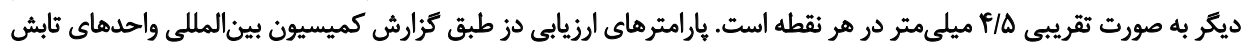
(ICRU)

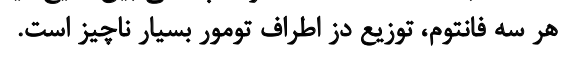

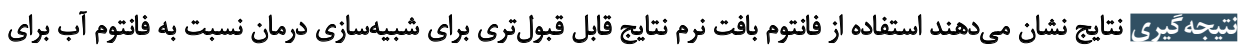

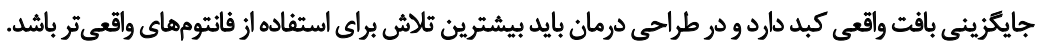

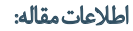

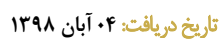

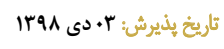

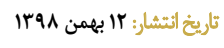

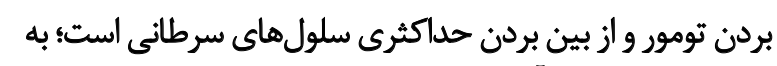

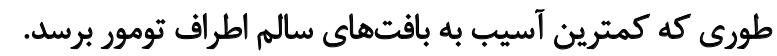

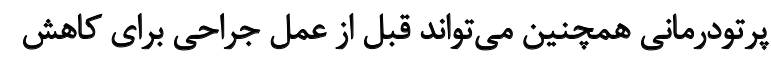

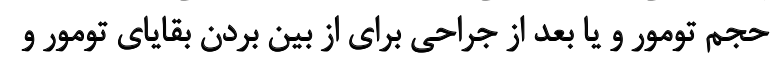

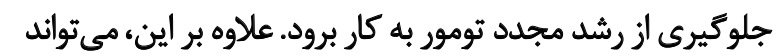

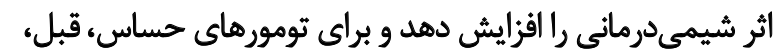
بعد و همزمان با شيمى درمانى استفاده شود.

در يرتودرمانى بهكاركيرى روشى كه بيشرين ثأثير بر درمان

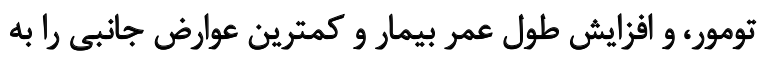

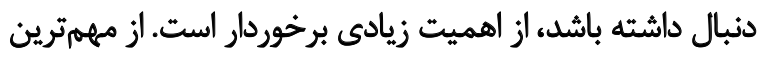

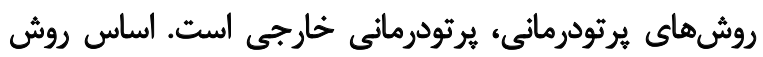

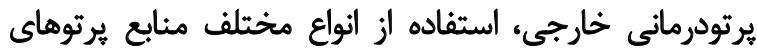

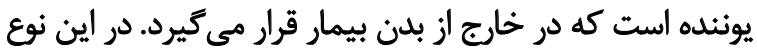

datio

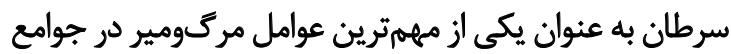

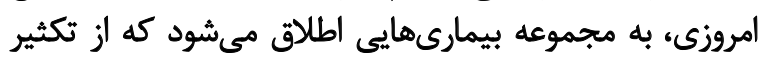

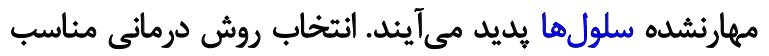

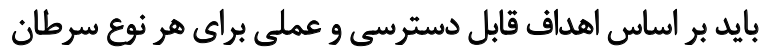

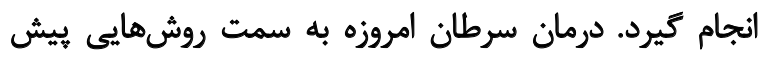

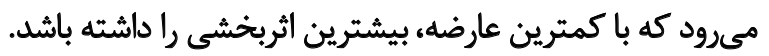

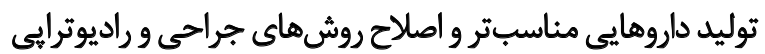

$$
\text { از جمله اين روشها هستيند. }
$$

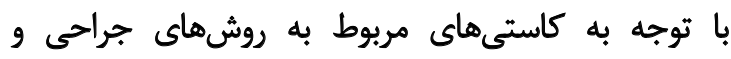

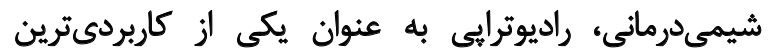

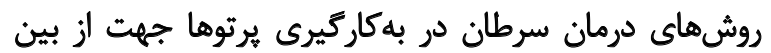




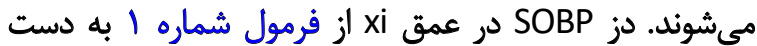

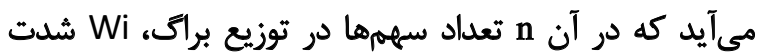

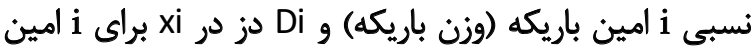
توزيع براك است.

1. $D\left(x_{i}\right)=\sum_{i=1}^{n} W_{i} D_{i}\left(x_{i}\right)$

تشكيل قله براك يهن بشده به دو صورت انجام مى ئيرد: الف)

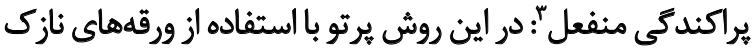

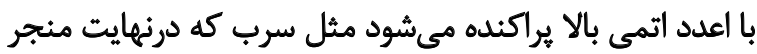

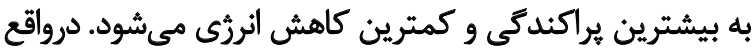

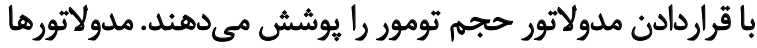

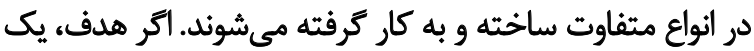

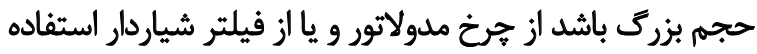

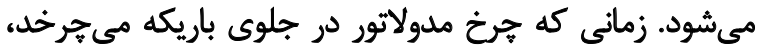

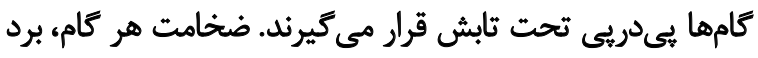

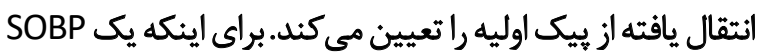

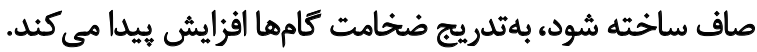

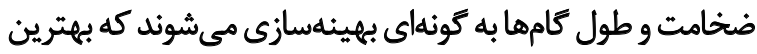

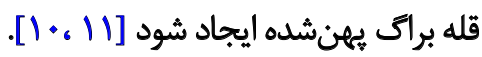

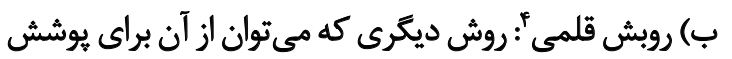

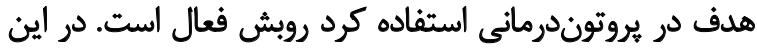

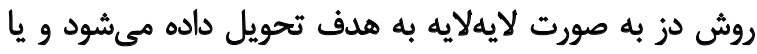

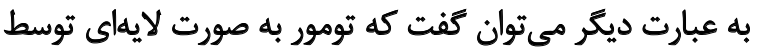

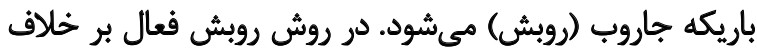

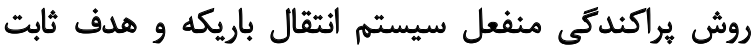

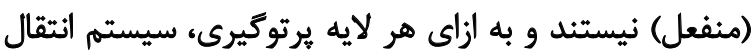

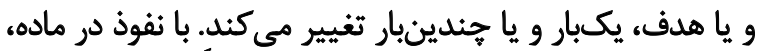

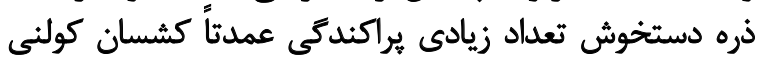

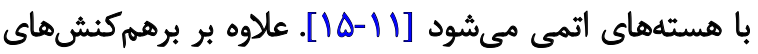

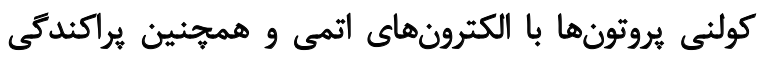

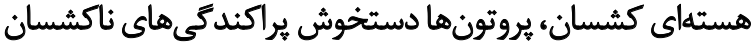

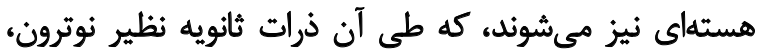

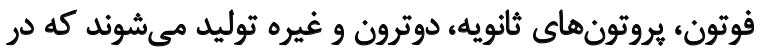

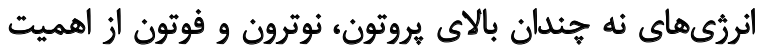

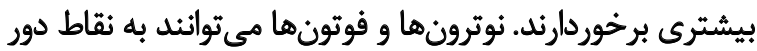

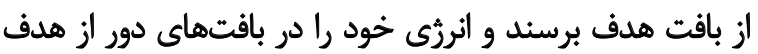

$$
\text { ذخيره كنئد. }
$$

ذرات ثانويه دو منشأ متفاوت دارند كه مي توانند موجب افزايش

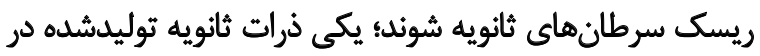

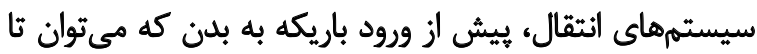

\section{Passive beam scattering}

4. Pencil beam scanning
يرتودرمانى منبع هرتوزا مى تواند شامل الكترون، نوترون، فوتون و

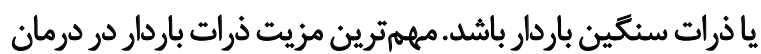

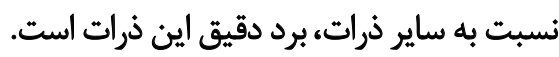

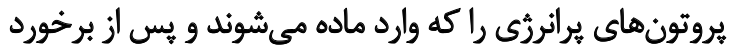

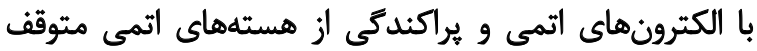

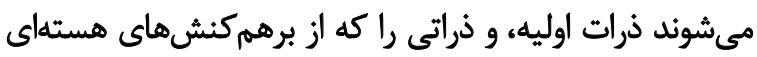

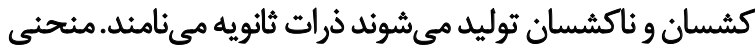

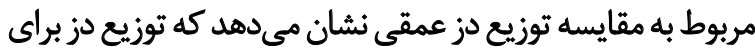

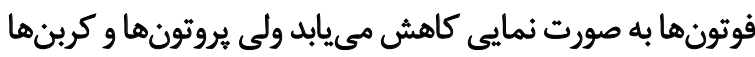

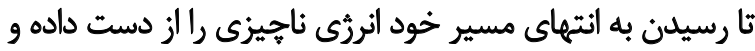

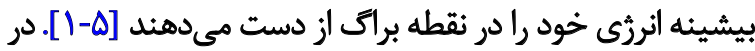

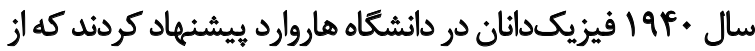

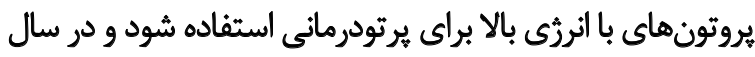

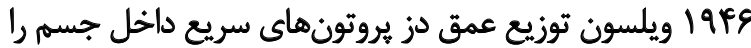

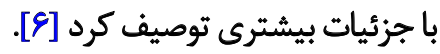

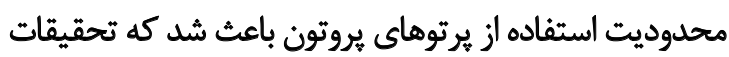

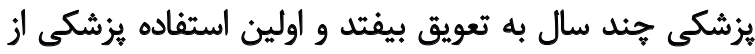

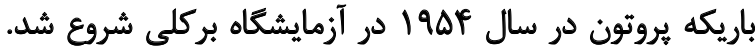

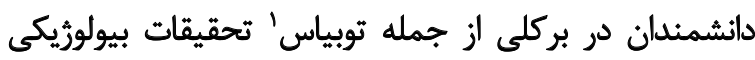

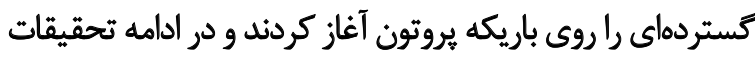

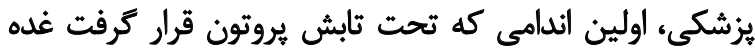

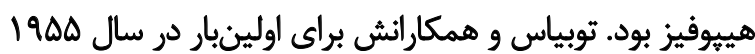

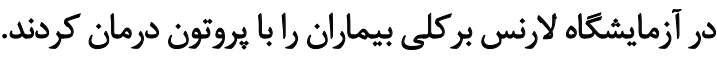
سيكلوترون جديد در دانشكاه آيسالا در سوئد، تحقيقاتى كه

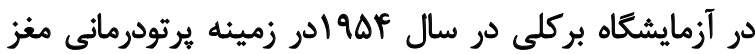

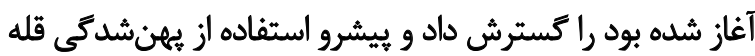

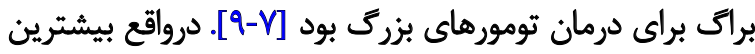

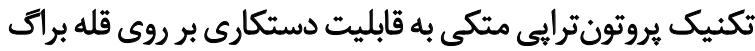

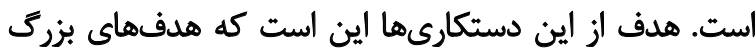

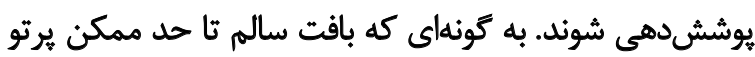

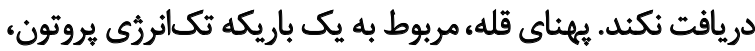

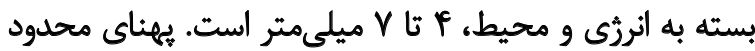

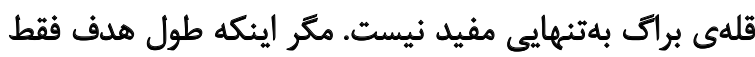

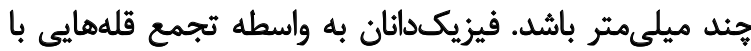

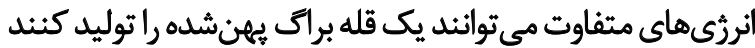

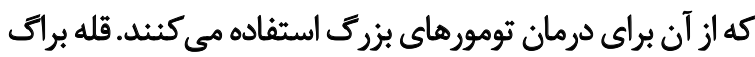

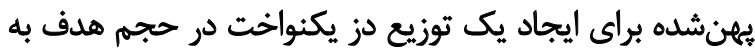

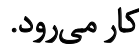

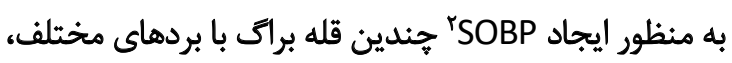

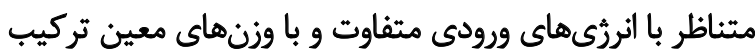

1. Tobias

2. Spread Out Bragg Peak 


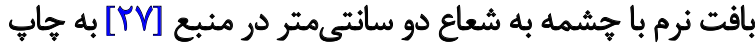

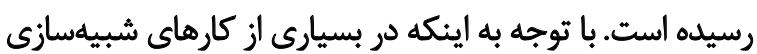

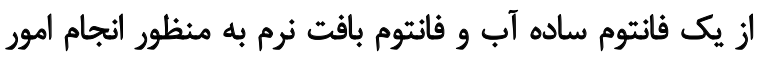

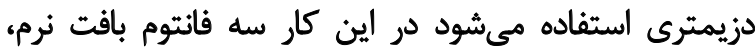

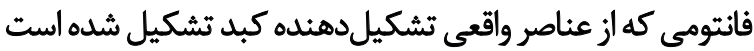

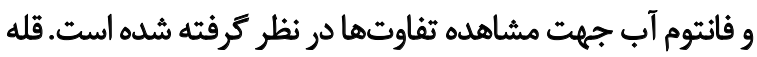

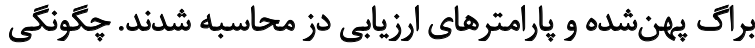

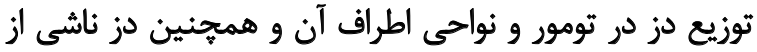

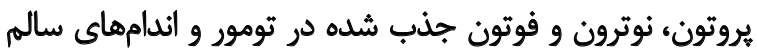

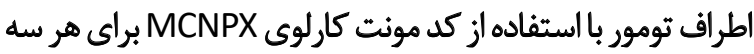
فانتوم محاسبه و به مقايسه نتايج يرداخته شده است.

\section{مواد ورش روشا}

هدف درمانى، به صورت تومورى كروى با شعاع دو سانتىمتر

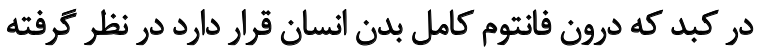

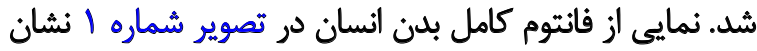

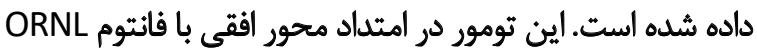

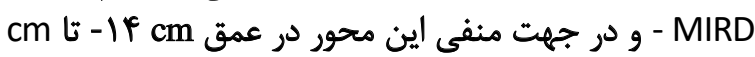

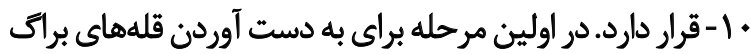

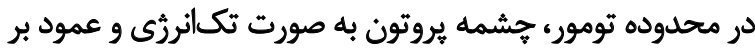

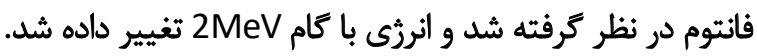

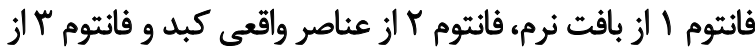

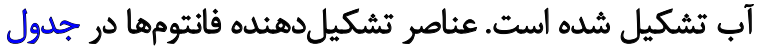

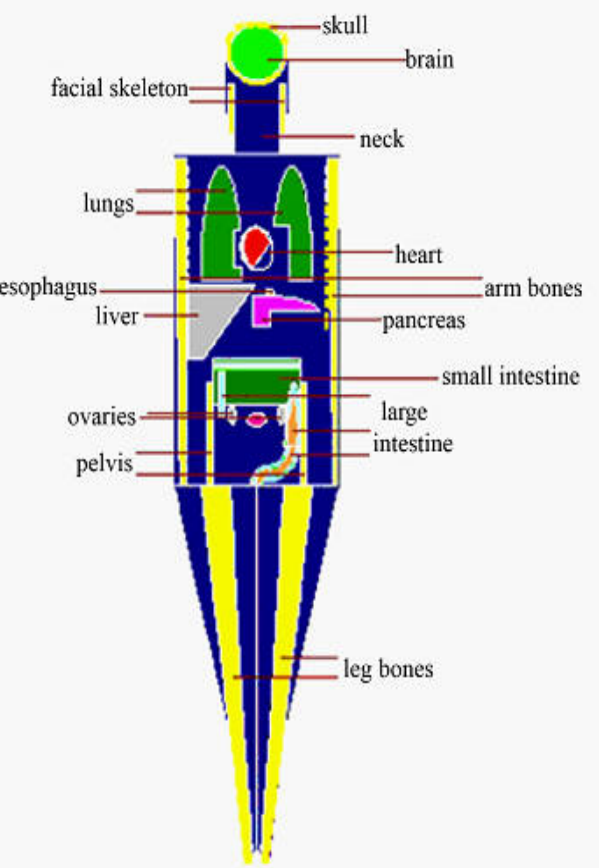

حدودى با قراردادن حفاظهاى مناسب نسبت به حذف آنها

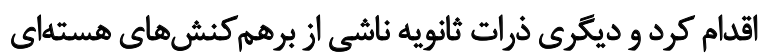

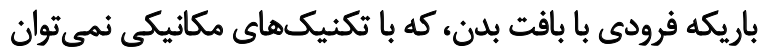

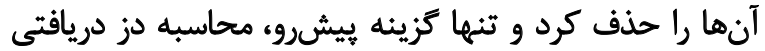

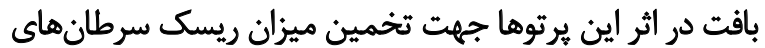

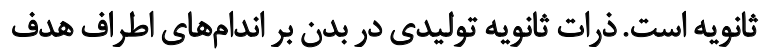

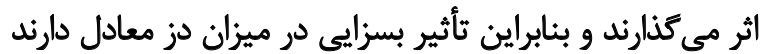

[19-19]

كبد بزر كترين غده بدن است كه در فرايند بروتئينسازى و

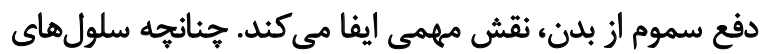

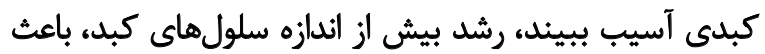

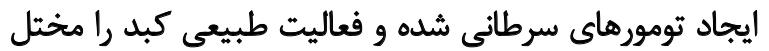

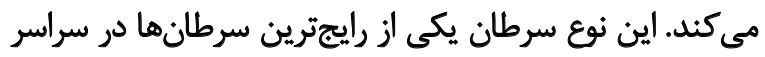

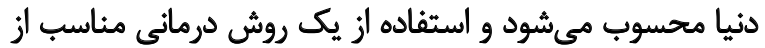

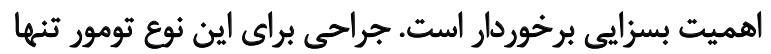

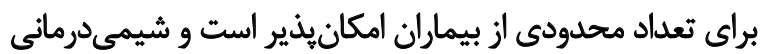

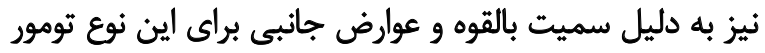

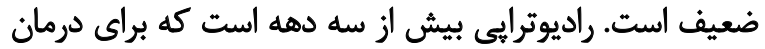

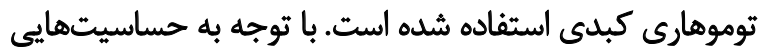

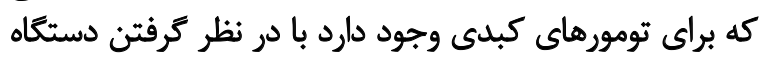

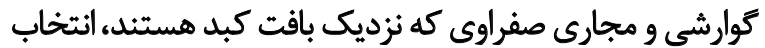
روش برتودرمانى مناسب بسيار مهم است نزديك بافت كئ

در ميان روشهاى مختلف، يروتوندرمانى به دليل ورئ واكذارى ئري

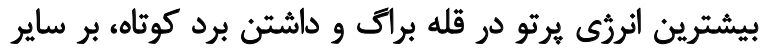

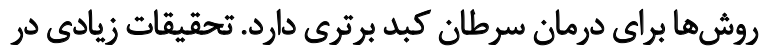

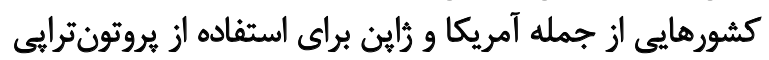

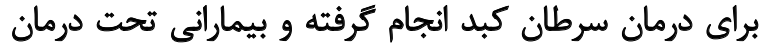

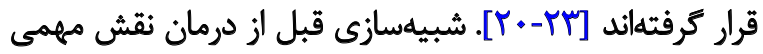

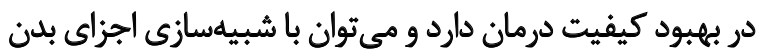

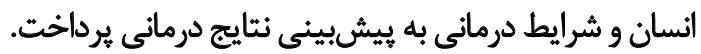
به دستَّاه يا الكّوى آزمايشىاى كه بدن انسان يا قسمتى از

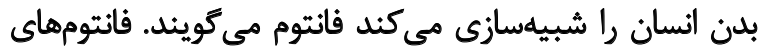

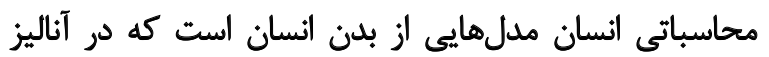

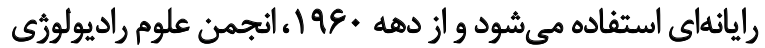

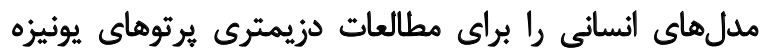

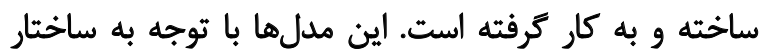

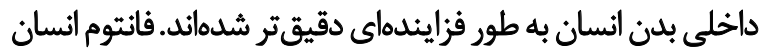

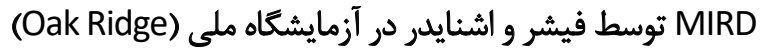

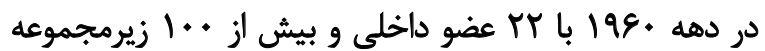

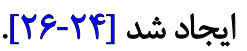

در اين كار سعى شده است با شبيهسازى كبد در فانتوم كامل

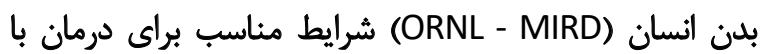

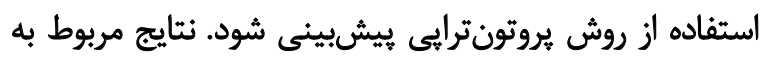


جدول l. عناصر تشكيلدهنده سه فانتوم

\begin{tabular}{|c|c|c|c|c|}
\hline \multirow{2}{*}{ فاتتوم } & \multicolumn{2}{|c|}{ قايتوم Y } & \multirow{2}{*}{ 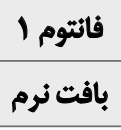 } & \multirow{2}{*}{ عناصر } \\
\hline & يوست & كبد & & \\
\hline.$/ 1119$ & 1. & $1 . / r$ & 1. Reaf & $\mathrm{H}$ \\
\hline- & $r \cdot / e$ & $15 / 9$ & Tr/FET & $C$ \\
\hline- & $e / r$ & $\Psi$ & rppq. & $\mathbf{N}$ \\
\hline.$|M A|$ & sto & VIV & gr/ATA & 0 \\
\hline- & - & - & - & $F$ \\
\hline- & $\cdot \pi$ &.$/ r$ &.$/ 11 Y$ & $\mathrm{Na}$ \\
\hline- & - & - & $.1 \cdot 1 r$ & $\mathrm{Mg}$ \\
\hline- & - & - & $.1 . r$ & $\mathrm{Si}$ \\
\hline- & .11 &.$/ r$ &.$/ 1 m$ & $\mathbf{P}$ \\
\hline- & $\cdot / r$ &.$/ r$ & $\cdot R+F$ & $\mathrm{~S}$ \\
\hline- & $\cdot / r$ &.$r$ &.$/ 1 \pi T$ & $\mathrm{Cl}$ \\
\hline- &.$/ 1$ &.$/ r$ & $\cdot R \cdot A$ & K \\
\hline- & - & - & $.1 \cdot \pi$ & $\mathrm{Ca}$ \\
\hline- & - & - & $+1 \cdot+\Delta$ & $\mathrm{Fe}$ \\
\hline- & - & - & $\cdot \theta+\cdot r$ & $\mathrm{Zn}$ \\
\hline- & - & - & $+1++1$ & $\mathrm{Rb}$ \\
\hline- & - & - & $+1++1$ & $\mathrm{Zr}$ \\
\hline
\end{tabular}

در ابتدا و انتهاي طيف.

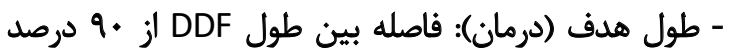

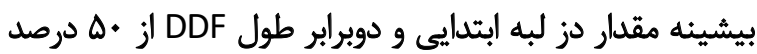
بيشينه مقدار دز در انتهاى طيف.

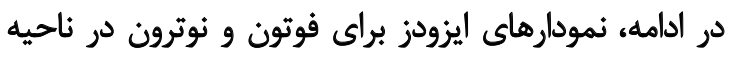

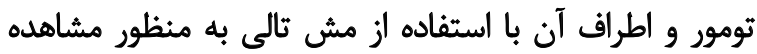

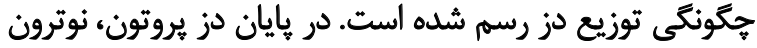

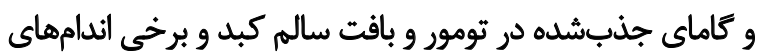

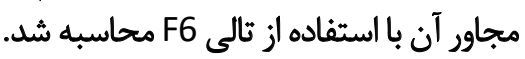

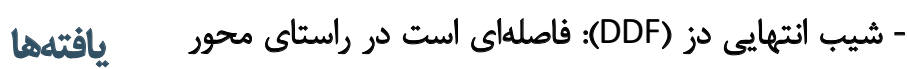

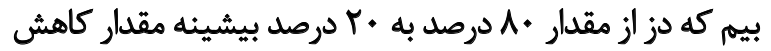
نتايج در هند قسمت ارائه شدهاند كه شامل به دست آوردن

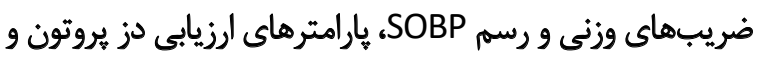

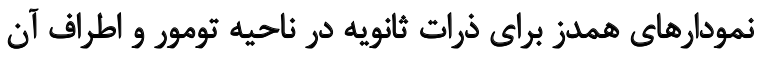

شماره آورده شدهاند [YN]. شبيلهازى درمان با انرزىهاى مختلف جشمه انجام شده و

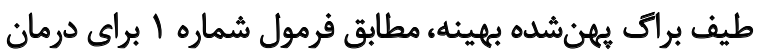

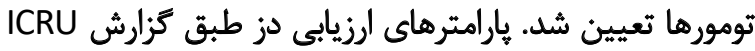

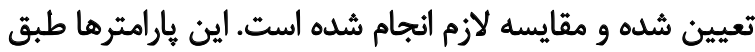

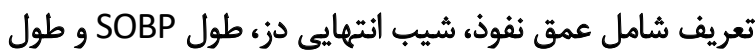
هدف است كه در ادامه توضيح داده شدهاند.

- عمق نفوذ ('d90): عمق در طول طيف تا نقطه +9 درصد از

$$
\text { بيشيئه مقدار دز در انتهاى طيف. }
$$

- طول SOBP (m90) فاصله بين • • 

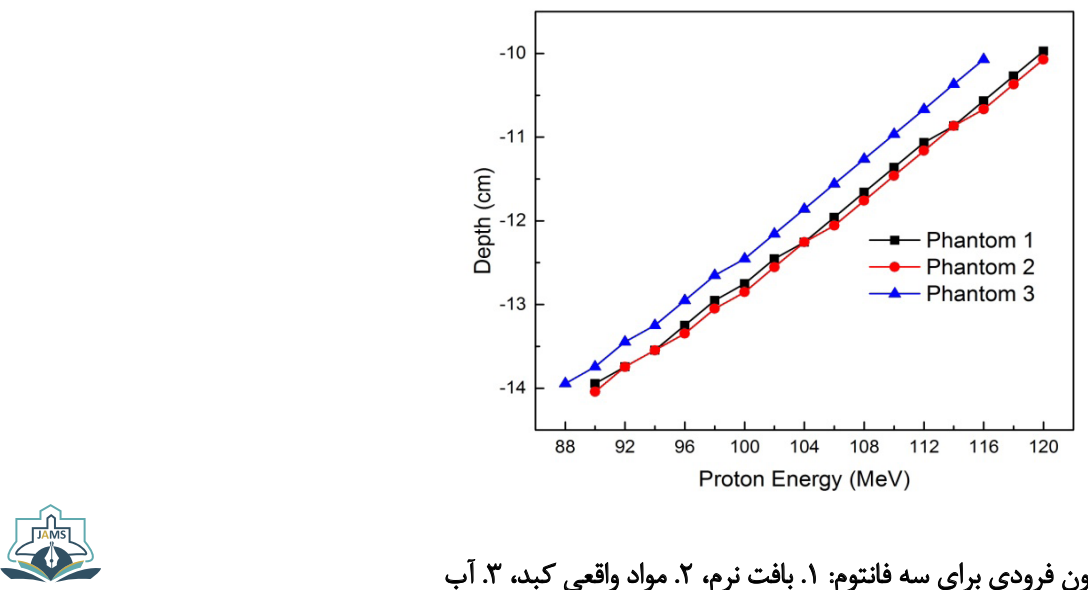

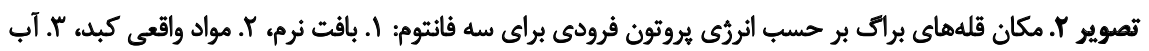

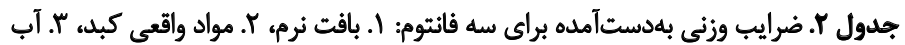

\begin{tabular}{|c|c|c|c|}
\hline \multicolumn{4}{|c|}{ ضرايب وزنى } \\
\hline فانتوم" & فائتوم Y & فانتوم & انروى (MeV) \\
\hline- & 1 & 1 & ir. \\
\hline- &.$/ M V A$ & $+/$ rAV & 111 \\
\hline 1 & - /YAQ & $\cdot / r V$ & 118 \\
\hline / /YQY & $\cdot / 4 \cdot 9$ & - /MYO & lif \\
\hline - ITEP &.$/ 194$ &.$/ 19$ & $11 \%$ \\
\hline.$/ M$ & - / IAr & $.|| \Delta \mid$ & 11. \\
\hline. Mer &.$/ N F$ &.$/ 1 m e$ & $1 \cdot 1$ \\
\hline ./IFF &.$/ M T$ &.$/ I T Y$ & 1.8 \\
\hline - /rta &.$/ 1 \cdot 9$ & $\cdot / 1 \cdot 1$ & $1+f$ \\
\hline / Ire & $\cdot N \cdot r$ & .1 .91 & $1+r$ \\
\hline .1 .97 & $\mathscr{H} / \mathrm{AP}$ & .1 .99 & $1 .$. \\
\hline / Ar & . $/ A r$ & $.1 \cdot \mathrm{VA}$ & 4 \\
\hline .1 .94 &.$/ . V e$ & $\cdot 1 \cdot M$ & $q$ \\
\hline $1 \cdot 18$ & 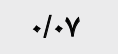 & $/ \cdot v^{r}$ & 9) \\
\hline .84 & $.1 \cdot \Delta A$ & /. $\Delta H^{H}$ & 9Y \\
\hline \% ve & $\cdot \mid \cdot r)$ & +1.88 & 9. \\
\hline$+1+p q$ & - & - & $M$ \\
\hline
\end{tabular}



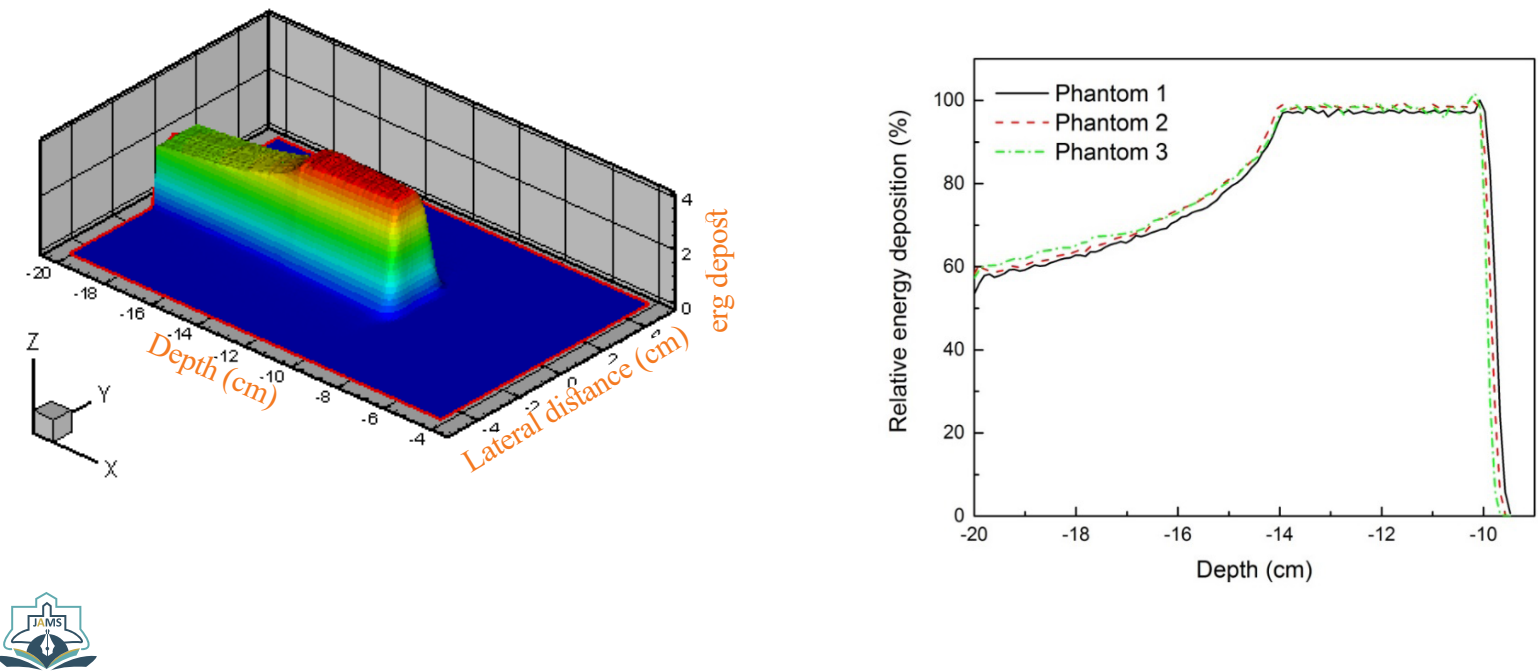

تصوير r. PBOS بهدست آمده بر اساس ضرايب جدول شماره r و فرمول شماره ا براى يوشش كامل تومور براى فائتومها، راست: توزيع دز سهبعلى، جب: توزيع دز عمقى

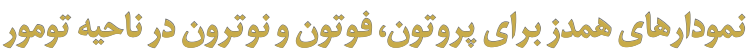

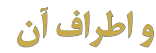

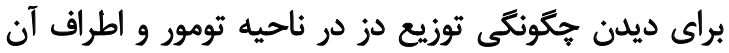

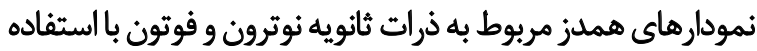

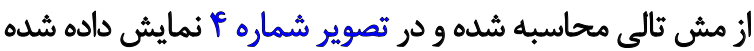

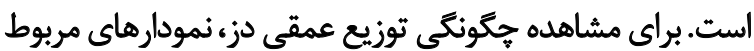

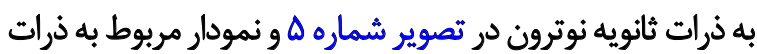

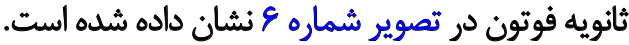

نمودارهاى همدز نشان مي دهند نوترونها بيشترين مقدار دز

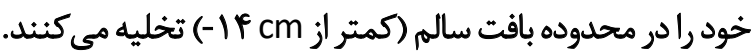

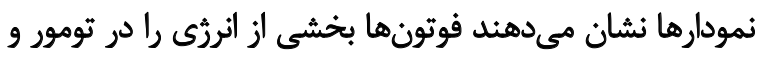

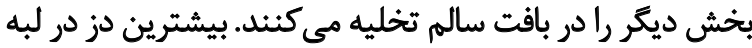
تومور و در عمق (cm) أ ا - تخليه شده است.

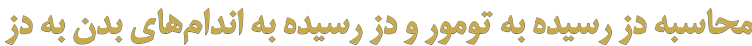

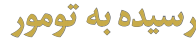

در اين قسمت دز تخليهشده ناشى از يروتون، نوترون و فوتون در
است كه به ترتيب توضيح داده شدهاند.

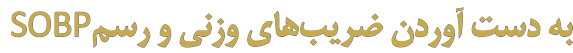

انرريى قلههاى براكى و مكانهاى مربوط به قلهها در تصوير

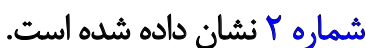

براى فانتوم شماره ا و ب قله ماى براتى در بازهى انرزى 120

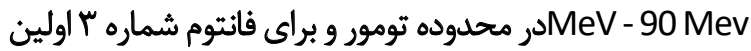
قله براى در سطح تومور در انرثى در محدوده تومور در انرئى 116MeV است.

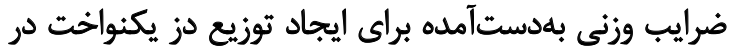

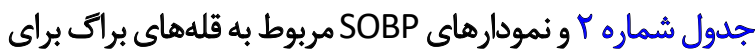
سه فانتوم در تصوير شماره ب r رسم شده است.

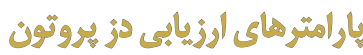

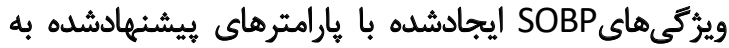

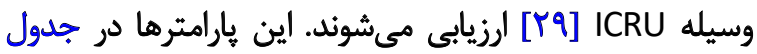
شماره r نشان داده شده است.

جدول با. يارامترهاي محاسبهشده جهت ارزيابى توزيع دز يروتون براي SOBP هاى طراحى شده بر اساس كزارش ICRU

\begin{tabular}{|c|c|c|c|}
\hline قاتنومب & فائتوم Y & | & يار امترهاي الرزيابى بيم (cm) \\
\hline 1. & 1.1 .1 & 1.1 .9 & d90 \\
\hline.$/ 1 V$ &.$/ V$ &.$/ I V$ & DDF \\
\hline fRr & $F / M F$ & $f / r q$ & $\mathrm{~m} 90^{\prime}$ \\
\hline F/Fq & r/NE & r/ar & طول هدف \\
\hline
\end{tabular}



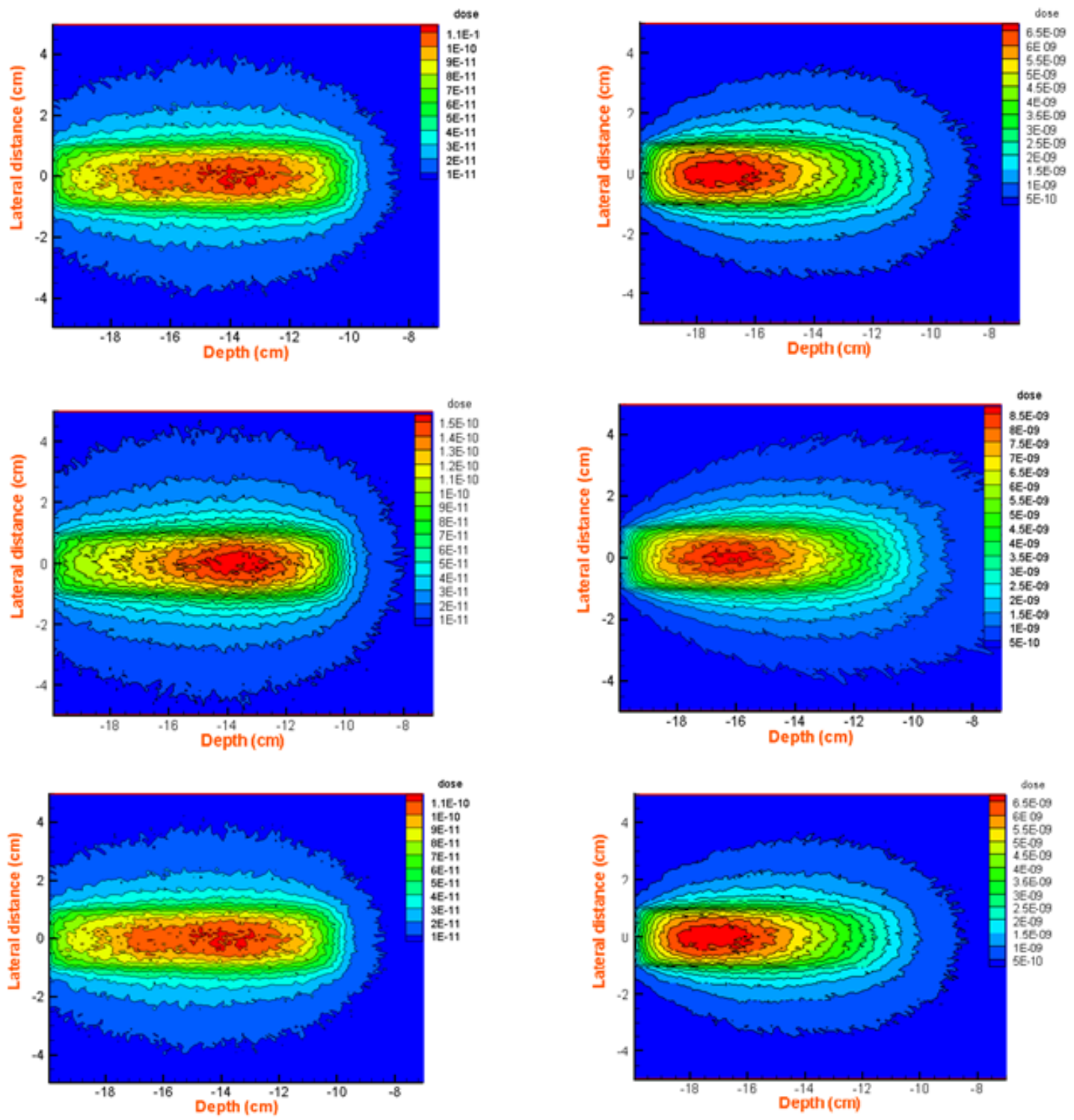

ints

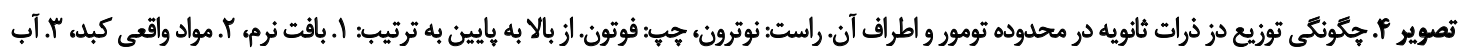

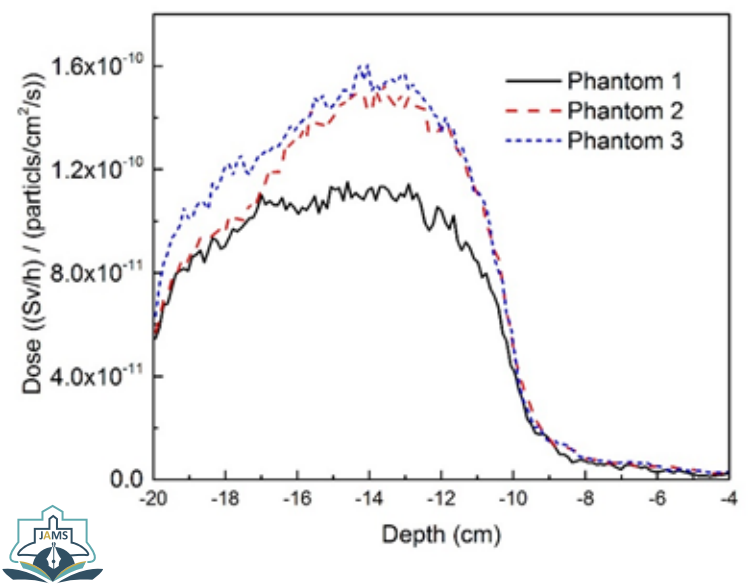

تصوير و. دز عمقى مربوط به فوتونهاي ثائويه براي فائتومها به ترتيب: 1.

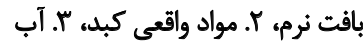
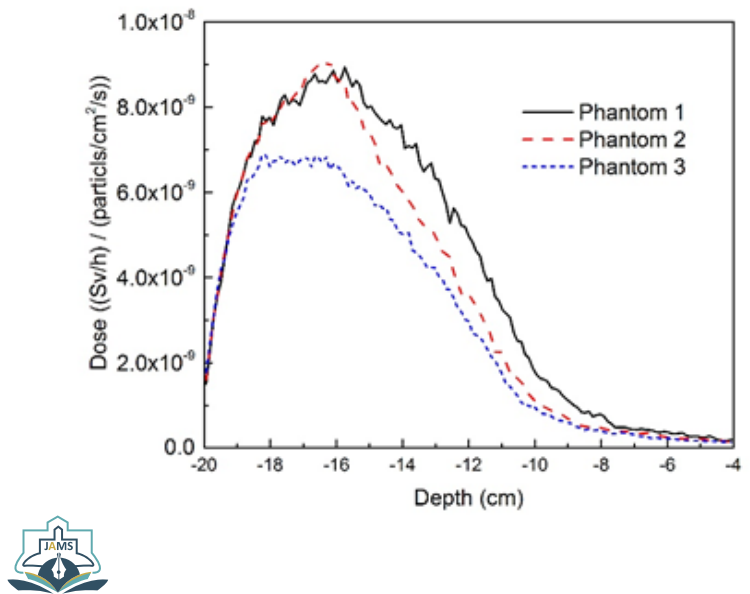

تصوير ه. دز عمقى مربوط به نوترونهاي ثائويه براي فائتومها به ترتيب: 1.

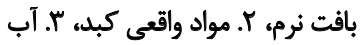


جدول F. ميزان دز رسيده به تومور و اعضاى بدن و مجموع دز ناشى از بروتون و ذرات ثانويه نوترون و فوتون

\begin{tabular}{|c|c|c|c|c|}
\hline \multicolumn{3}{|c|}{$x^{1+}-1$} & \multirow{2}{*}{ اندام } & \multirow{2}{*}{ شماره اندام } \\
\hline فائتوم r & فاتتوم Y & فانتوم 1 & & \\
\hline$r(\mid \Delta \times)^{\circ}$ & $Y(\cdot V \times) *^{\circ}$ & $r / \mid r \times 10^{\circ}$ & تومور & 1 \\
\hline$r / M F x^{r-1}$ & $r / V E \times{ }^{r-1}$. & $r / 9 x^{r-1}$ & كبد & r \\
\hline$\left.F / T V x^{r-}\right)$. & $r / \cdot r r^{r-1}$. & $r / \cdot r x^{r-} \mid$. & دنده & r \\
\hline V $/ \Delta F X^{H-} \mid$. & V/aff $x^{r-1}$ & $1 / \Delta r x^{r-1}$ & يوست شكم & f \\
\hline$r / r \nabla x^{\varphi}-1$. & $1 / \mu r x^{r-1}$ & $r / M f x^{p-1}$ & شكم & $\Delta$ \\
\hline$V /\left(1 / x^{2-}\right)$ & $9 / 1 \times x^{-1}-1$. & $1 / r V x^{p-1}$ & كيسه صفرا & 8 \\
\hline$\left.\Delta / \cdot r x^{\Delta-}\right)$ & $g / V\left(T x^{\theta-1}\right.$ & $V / F \Delta x^{\Delta-1}$ & قلب & $\gamma$ \\
\hline$T / 19 x^{\alpha-1}$ & $r / 9 \mid x^{\Delta-1}$ & T/RTX $x^{\Delta-1}$. & كليه & $\wedge$ \\
\hline T/AS $x^{\Delta-1}$ & $T / m x^{\alpha-1}$ & $r / \pi x^{\Delta-1}$. & ates & 9 \\
\hline $\mid\left(\left|\Delta x^{\Delta-}\right|\right.$ & $r / \Delta Q x^{\Delta-1}$ & $r / I V x^{\Delta-1}$ & آدرئال & 1. \\
\hline $1 / \Delta A x^{\Delta-1}$ & $r / \cdot f x^{\infty}-1$. & $r / A V x^{a-1}$ & يائكراس & 11 \\
\hline $8 / 1 x^{8}-1$ & $9 / f a x^{5}-1$ & $|/ T| x^{\Delta-1}$ & مرى & ir \\
\hline$N \mid x^{8}-1$ & $1 / \cdot r x^{-a-1}$ & $1 / 14 x^{a-1}$ & روده كوجى & ir \\
\hline$V / V\left(x^{8}-1\right.$. & $9 / p+x^{g}-1$ & $9 / 1 x^{8}-1$ & شش راست & if \\
\hline $4 / \mid x^{8}-1$ & $1 / \pi+x^{8}-1$ & $\Delta / r+x^{8}-1$ & شش جَب & 10 \\
\hline$r / f a x^{8}-1$. & $m / 9 f x^{9}-1$. & $f / 7 q x^{8}-1$ & تخملانها & is \\
\hline$r /+1 x^{8}-1$ & $r / A C x^{5}-1$. & r/grts -1 . & رحم & IV \\
\hline$m / 1 f x^{5}-1$ & $m / 9+x^{5}-1$ & $r / v q x^{5}-1$. & سينهها & $M$ \\
\hline$r / \cdot V x^{8}-1$ & $r / 8 \cdot x^{5}-1$. & $r / r x^{9}-1$ & مثانه & 19 \\
\hline F/rAx $x^{r}-1$ & $4 / 98 x^{\gamma}-1$ & $F / T \Delta x^{\gamma}-1$ & اندام تثاسلى & $r$. \\
\hline $1 / m x^{y}-1$ & $r / r A x^{r}-1$ & $r / m x^{2}-1$ & سر & $M$ \\
\hline $1 / x+x^{r}=1$. & $r / 1 \Delta x^{\gamma}-1$. & $1 / 9 x^{2}-1$ & مغز & $\pi$ \\
\hline $1 / 4 A x^{\gamma}-1$ & $1 / 8 r x^{r}-1$ & $1 / \Delta \Delta x^{2}-1$ & ياها & r \\
\hline
\end{tabular}

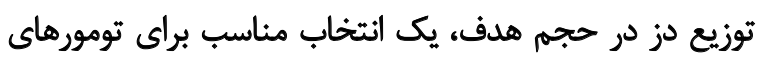

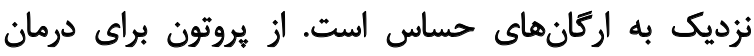

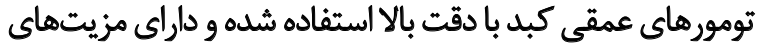

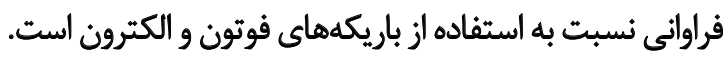

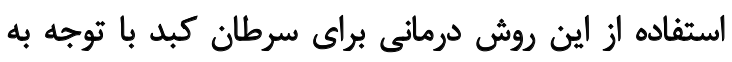

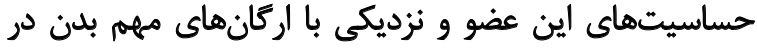

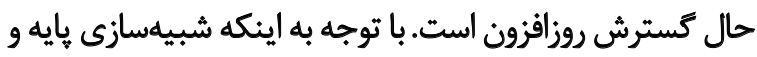

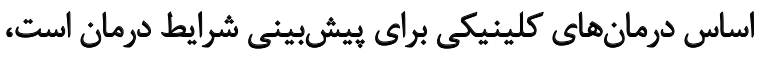

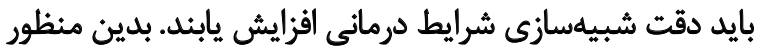

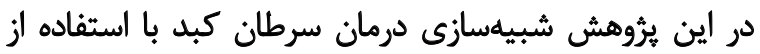

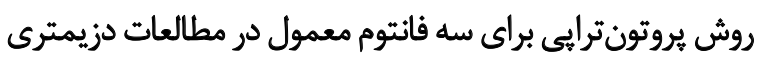

تومور و بسيارى از اندامهاى بلن براى سه فانتوم محاسبه شده و در استر

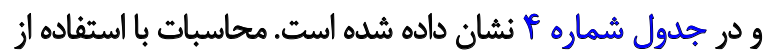

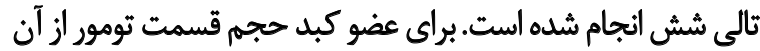

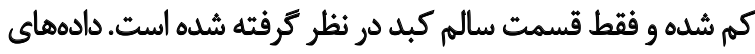

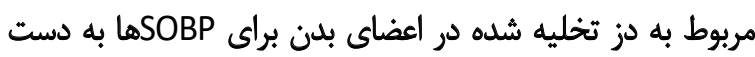

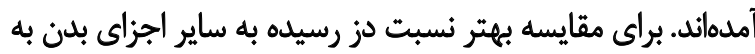
تومور محاسبه شده ودر تصوير شماره لنشان داده شده است. بحث

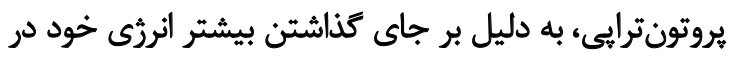

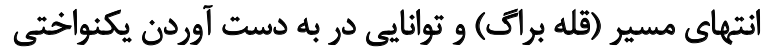


تفاوتها ناجيز بود. شيب انتهايى دز هرجه كمتر باشد بهتر است؛

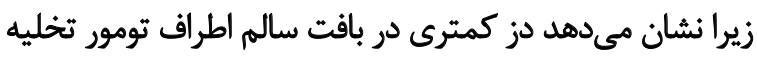

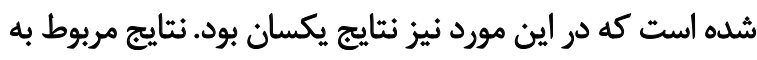

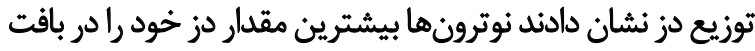

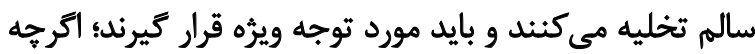
براى ذرات ثانويه فوتون بيشترين مقدار دز در ناحيه تونيه تومور تخليه ترنيه

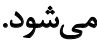

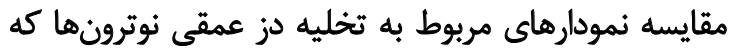

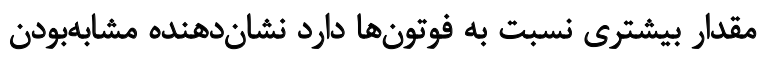

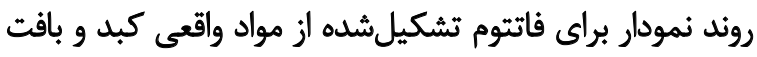

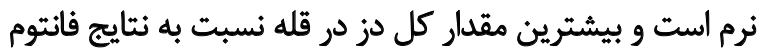

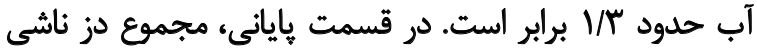

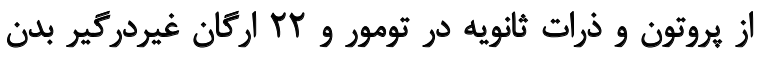
محاسبه شد. تثيجلميرى

محاسبه دز در اركانهاي مختلف بدن نشان دادند اكثر اجزاي

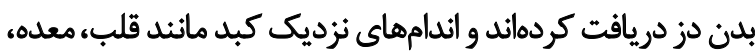

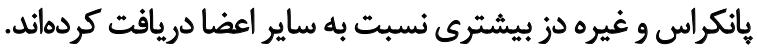

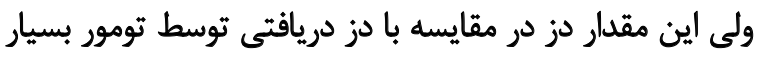

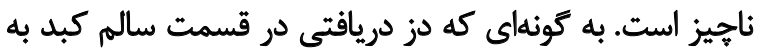

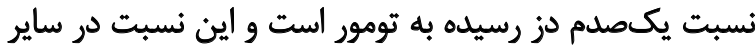

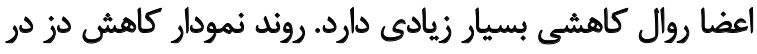

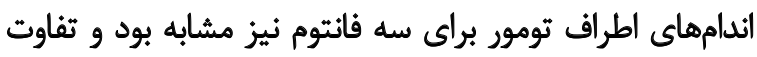

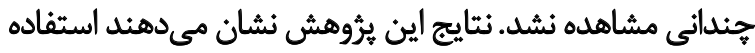

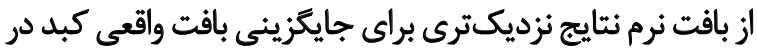

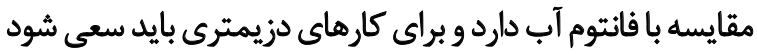
كه از فانتومهاي واقعى بانتر استفاده شود.

ملاحظات اخلاقى

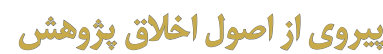

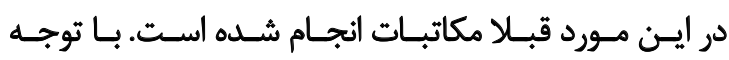

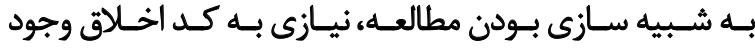

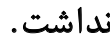

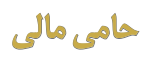

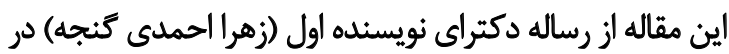

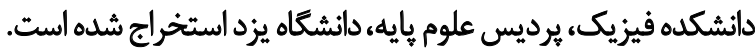

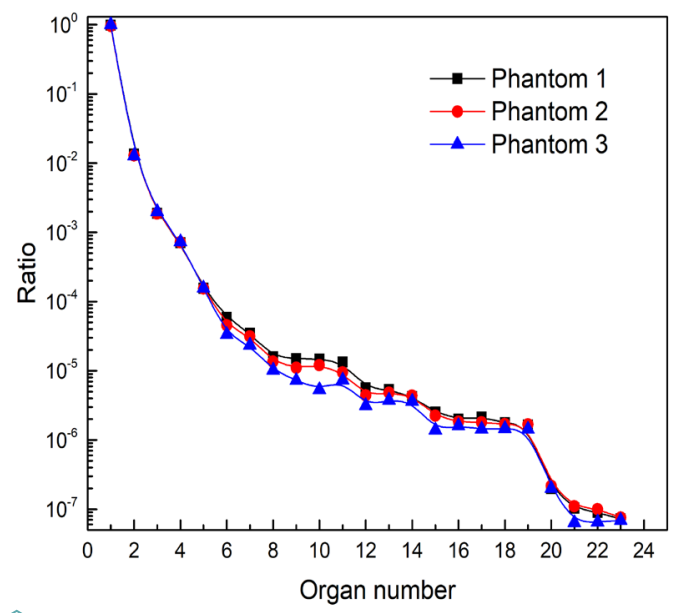

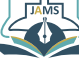

تصوير لا نسبت دز تخليهشده در ساير اندامها به تومور براي سه فائتوم

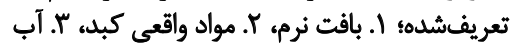

متشكل از بافت نرم، مواد اصلي كبد و آب مورد بروسي قرار كرفت

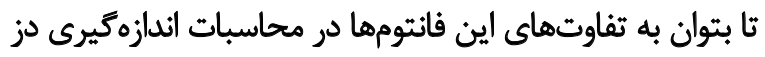
دست يافت.

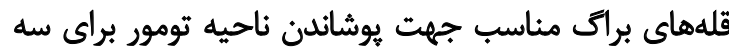

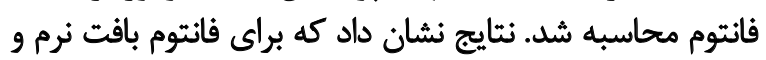

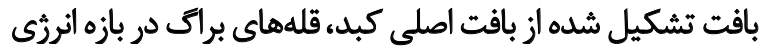
116 120 MeV - 90 MeV MeV - 88 MeV

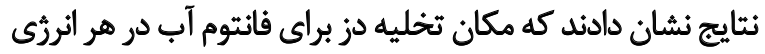

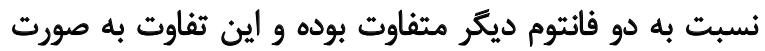

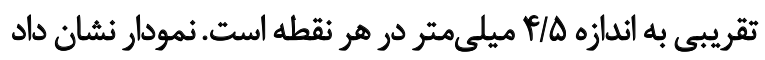

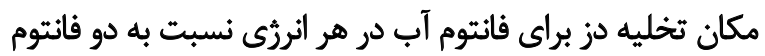

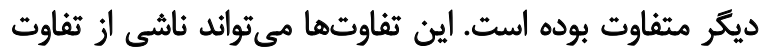

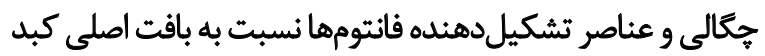
باشد. - المي

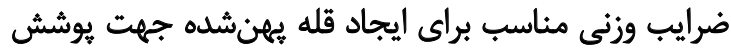

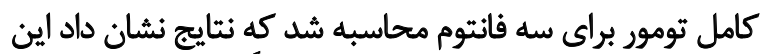

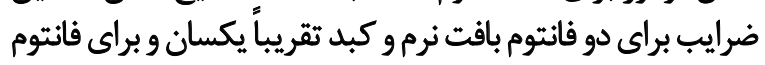

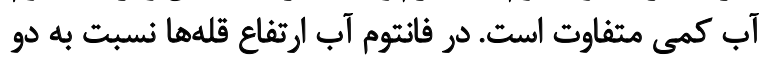

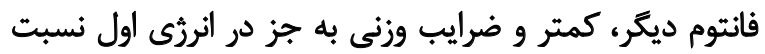

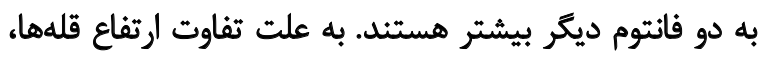

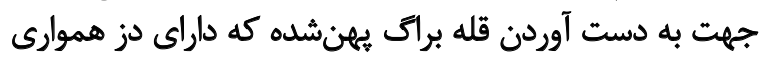

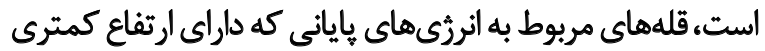

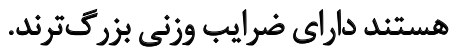

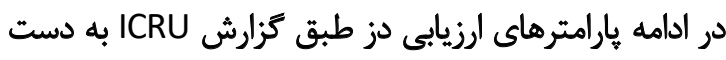

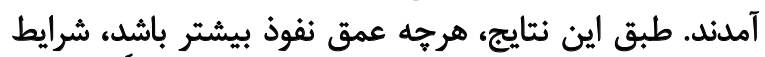

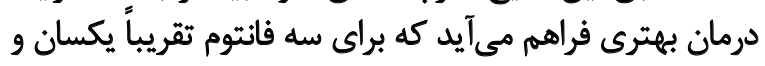




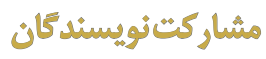

$$
\begin{aligned}
& \text { تمــام نويســندكان در آمادهســازي ايــن مقالــه مشــاركت } \\
& \text { داشُـــتهاند. } \\
& \text { ctio }
\end{aligned}
$$

بدينوسيله نويسندكان تصريح مى كنئل كه هيج كونه تضاد منافعى در خصوص يثروهش حاضر وجود ندارد. 


\section{References}

[1] Doyen J, Falk AT, Floquet V, Herault J, Hannoun-Levi JM. Proton beams in cancer treatments: Clinical outcomes and dosimetric comparisons with photon therapy. Cancer Treat Rev. 2016; 43:104-12. [DOI:10.1016/j. ctrv.2015.12.007] [PMID]

[2] Larsson B. Proton and heavy ion therapy. Exp Suppl. 1975; 24:414-8. [DOI:10.1007/978-3-0348-5520-4_88] [PMID]

[3] Suit H, DeLaney T, Goldberg S, Paganetti H, Clasie B, Gerweck L, et al. Proton vs carbon ion beams in the definitive radiation treatment of cancer patients. Radiother Oncol. 2010; 95(1):3-22. [DOI:10.1016/j.radonc.2010.01.015] [PMID]

[4] Levin WP, DeLaney TF. Chapter 19 - Charged particle radiotherapy. In: Gunderson LL, Tepper JE, editors. Clinical Radiation Oncology (Third Edition). Philadelphia: W.B. Saunders. 2012: 361-76. [DOI:10.1016/B978-14377-1637-5.00019-5]

[5] Seif F, Bayatiani MR. Cancer and radiotherapy. J Arak Univ of Med Sci. 2018; 21(4):1-5

[6] Wilson RR. Radiological use of fast protons. Radiology. 1946; 47(5):48791. [DOI:10.1148/47.5.487] [PMID]

[7] Peschel RE. Notice: recently published book: proton therapy and radiosurgery, H. Breuer, B.J. Smit, springer-verlag; 2000. Int J Cancer. 2000 90(2):112. [DOI:10.1002/(SICI)1097-0215(20000420)90:23.0.CO;2-X]

[8] Khan FM. The physics of radiation therapy. Philadelphia: Lippincott Williams \& Wilkins; 2010

[9] Lawrence JH, Tobias CA, Born JL, McCombs RK, Roberts JE, Anger HO, et al. Pituitary irradiation with high-energy proton beams: A preliminary report. Cancer Res. 1958; 18(2):121-34. [PMID]

[10] Abril I, de Vera P, Garcia-Molina R, Kyriakou I, Emfietzoglou D. Lateral spread of dose distribution by therapeutic proton beams in liquid water. : Nucl Instrum Methods Phys Res B. 2015; 352:176-80. [DOI:10.1016/j. nimb.2014.11.100]

[11] Paganetti H. Proton Beam therapy. Florida: CRC Press. 2016. [DOI:10.1088/978-0-7503-1370-4ch1]

[12] Klodowska M, Olko P, Waligorski MP. Proton microbeam radiotherapy with scanned pencil-beams--Monte Carlo simulations. Phys Med. 2015; 31(6):621-6. [DOI:10.1016/j.ejmp.2015.04.006] [PMID]

[13] Paganetti H. Proton Beam therapy. Florida: CRC Press. 2016 [DOI:10.1088/978-0-7503-1370-4ch1]

[14] Bonfrate A, Farah J, De Marzi L, Delacroix S, Herault J, Sayah R, et al. Influence of beam incidence and irradiation parameters on stray neutron doses to healthy organs of pediatric patients treated for an intracranial tumor with passive scattering proton therapy. Physica Med. 2016; 32(4):590-9. [DOI:10.1016/j.ejmp.2016.03.009] [PMID]

[15] Moteabbed M, Yock TI, Depauw N, Madden TM, Kooy HM, Paganetti $\mathrm{H}$. Impact of spot size and beam-shaping devices on the treatment plan quality for pencil beam scanning proton therapy. Int J Radiat Oncol Biol Phys. 2016; 95(1):190-8. [DOI:10.1016/j.jirobp.2015.12.368] [PMID] [PMCID]

[16] Schneider U, Agosteo S, Pedroni E, Besserer J. Secondary neutron dose during proton therapy using spot scanning. Int J Radiat Oncol Biol Phys. 2002; 53(1):244-51. [DOI:10.1016/S0360-3016(01)02826-7]

[17] Schneider U, Halg RA, Lomax T. Neutrons in active proton therapy: Parameterization of dose and dose equivalent. Z Med Phys. 2017; 27(2):113-23. [DOI:10.1016/j.zemedi.2016.07.001] [PMID]
[18] Islam MR, Zheng Y, Collums TL, Monson JM, Ahmad S, Benton ER. Measurement and simulation of secondary neutrons from uniform scanning proton beams in proton radiotherapy. Radiat Meas. 2017; 96:8-18. [DOI:10.1016/j.radmeas.2016.11.008]

[19] Agosteo S, Birattari C, Caravaggio M, Silari M, Tosi G. Secondary neutron and photon dose in proton therapy. Radiother Oncol. 1998; 48(3):293-305 [DOI:10.1016/S0167-8140(98)00049-8]

[20] Fukumitsu N, Okumura T, Takizawa D, Makishima H, Numajiri H, Murofushi $\mathrm{K}$, et al. Proton beam therapy for metastatic liver tumors. Radiother Oncol. 2015; 117(2):322-7. [DOI:10.1016/j.radonc.2015.09.011] [PMID]

[21] Arscott WT, Thompson RF, Yin L, Burgdorf B, Kirk M, Ben-Josef E. Stereotactic body proton therapy for liver tumors: Dosimetric advantages and their radiobiological and clinical implications. Phys Imaging Radiat Oncol. 2018; 8:17-22. [DOI:10.1016/j.phro.2018.11.004]

[22] Hong TS, DeLaney TF, Mamon HJ, Willett CG, Yeap BY, Niemierko $A$, et al. A prospective feasibility study of respiratory-gated proton beam therapy for liver tumors. Pract Radiat Oncol. 2014; 4(5):316-22. [DOI:10.1016/j.prro.2013.10.002] [PMID] [PMCID]

[23] Chuong M, Kaiser A, Molitoris J, Romero AM, Apisarnthanarax S. Proton beam therapy for liver cancers. J Gastrointest Oncol. 2020; 11(1). [DOI:10.21037/jgo.2019.04.02]

[24] Gualdrini G, Ferrari P. Handbook of anatomical models for radiation dosimetry. Radiation protection dosimetry. 2011; 143(1):125-7. [DOI:10.1093/rpd/ncq333]

[25] Report of the task group on reference man ICRP Publication 23 (1975). Ann ICRP. 1980; 4(3-4). [DOI:10.1016/0146-6453(80)90047-0]

[26] Snyder WS, Fisher HL Jr, Ford MR, Warner GG. Estimates of absorbed fractions for monoenergetic photon sources uniformly distributed in various organs of a heterogeneous phantom. J Nuc Med. 1969; (Suppl. 3):7-52. [PMID]

[27] Ahmadi Ganjeh Z, Eslami-Kalantari M, Mowlavi AA. Dosimetry calculations of involved and noninvolved organs in proton therapy of liver cancer: A simulation study. Nucl Sciand Tech. 2019; 30(12):173 [DOI:10.1007/s41365-019-0698-8]

[28] White DR, Booz J, Griffith RV, Spokas JJ, Wilson IJ. Report 44. Journal of the International Commission on Radiation Units and Measurements. 2016; 23(1). [DOI:10.1093/jicru/os23.1.Report44]

[29] Prescribing, Recording, And Reporting Proton-Beam Therapy: Contents. J Int Comm Radiat Units Meas. 2007; 7(2). [DOI:10.1093/jicru/ ndm021] 